\title{
In-plane anisotropy in deformation micro-mechanism of commercially pure titanium during monotonic tension and cyclic loading
}

\author{
Atasi Ghosh \\ Indian Institute of technology Kanpur, Kalyanpur, Kanpur, Uttar Pradesh, 208016, India. \\ atasi@iitk.ac.in, http://orcid.org/0000-0001-8640-3561
}

\begin{abstract}
In the present investigation in-plane anisotropy in tensile and ratcheting behavior of cold rolled and annealed commercially pure titanium plate has been studied. Flat tensile and fatigue test specimen oriented at 0,45 , and 90 degree to the rolling direction from the rolling direction-transverse direction (RD-TD) plane of the plate has been machined out. Specimens with loading axis at 0,45 and 90 degree to $\mathrm{RD}$ have been designated as $0 \mathrm{~T}, 45 \mathrm{~T}$ and $90 \mathrm{~T}$ for tensile and $0 \mathrm{R}, 45 \mathrm{R}$ and $90 \mathrm{R}$ for fatigue. Owing to initial TD split basal texture of as received plate, $0 \mathrm{~T}$ sample has crystallographic direction $\langle 10 \overline{1} 0\rangle-\langle 11 \overline{2} 0\rangle$ aligned with loading axis. It shows lowest yield strength but highest ductility in monotonic tension. Although ultimate tensile strength (UTS) and strain to failure of samples 45T and 90T are similar, the former has significantly lower yield strength than the latter, indicating different strainhardening behavior due to different slip/twin activity. On the other hand, $0 \mathrm{R}$ sample exhibits longer ratcheting life while 90R sample accumulates highest ratcheting strain. This has been attributed to the formation of intersecting multi-variant twins, which increases fatigue crack propagation resistance during cyclic deformation of $\mathrm{OR}$ sample. Viscoplastic self-consistent (VPSC) simulations of one-cycle tension-compression-reload tension indicate alternating activity of pyramidal $<\mathrm{c}+\mathrm{a}>$ slip and extension twinning with loading cycle. The detwinning of extension twin during compression cycle induces cross slip activity, which causes rapid accumulation of strain leading to early fatigue failure of $45 \mathrm{R}$ and $90 \mathrm{R}$ sample.
\end{abstract}

KEYWORDS. Titanium; Anisotropy; Tensile; Ratcheting; VPSC; EBSD.

\section{OPEN ACCESS}

Citation: Ghosh, A., In-plane anisotropy in deformation micro-mechanism of commercially pure titanium during monotonic tension and cyclic loading, Frattura ed Integrità Strutturale, 48 (2019) 585-598.

Received: 28.11 .2018

Accepted: 28.02.2019

Published: 01.04.2019

Copyright: (C) 2019 This is an open access article under the terms of the CC-BY 4.0, which permits unrestricted use, distribution, and reproduction in any medium, provided the original author and source are credited.

\section{INTRODUCTION}

ommercially pure titanium (CP-Ti) sheet has various structural applications such as in offshore drilling platform, sheet and plate heat exchangers, airframe components etc. due to its good combination of mechanical properties like high specific strength, good formability along with superior corrosion resistance. However, the properties are 
strongly anisotropic even in polycrystalline material with random texture, due to low symmetry of hexagonal crystal structure of titanium. It influences tensile and fatigue properties of the component material made of titanium under multi-axial loading condition which ultimately decides their service life. Hence, it is necessary to understand the influence of initial texture on anisotropy in deformation micro-mechanism under tensile and cyclic loading conditions. In general, tensile deformation behaviour of CP-Ti has been studied in detail, [1-5] and recently, many investigations focusing on in-plane anisotropy of tensile and fatigue properties of CP-Ti have been carried out [6-11]. It has been observed that the strain hardening response of titanium is strongly influenced by composition, loading direction and sense of applied load. Tensile, compressive and cyclic tests carried out on rolled sheets of CP-Ti exhibit better tensile properties but poor high cycle fatigue life for rolling direction (RD) compared to the transverse direction (TD) sample [6, 8]. On the other hand, CP-Ti Grade 1 and Grade 2 sheets showed highest total elongation for 45 degree oriented specimen [9]. Simulation of stress-strain behavior under tension and compression tests of $\alpha$-Ti based on constitutive modeling captured non-symmetric and orthotropic mechanical response [10]. Significant anisotropy in biaxial deformation behavior of CP-Ti even after hydrostatic extrusion has been observed [11]. However, a change in strain path during various speed rolling routes, CP-Ti showed decrease in anisotropy of mechanical properties due to uniform shear deformation inspite of different tensile and compressive stresses [12].

The deformation micro-mechanism is controlled by the activation of number of slip and twin system in titanium [13]. The type of twin and their mechanism of nucleation, propagation, and growth are influenced by the direction and sense of loading and hence influence anisotropic response [14]. Thus, the nature of twin influence strain to failure under tensile load [15] and number of cycles to failure under stress [16] and strain control [17] cyclic load for different orientations. Therefore, in the light of the importance of anisotropy in the mechanical property, it is essential to obtain a thorough understanding of the effect of initial orientation on deformation micro-mechanism for phenomenon like ratcheting which has not been studied yet.

In the present investigation, the experimentally obtained stress- strain response under monotonic tensile and stress controlled cyclic loading has been complemented with state-of-the-art deformation microstructure characterization using electron backscatter diffraction (EBSD) and crystal plasticity simulations using the viscoplastic self-consistent (VPSC) for different in-plane orientations. The simulations provide insight about the contribution of various slip activity while EBSD provides perspective regarding the role of twins in anisotropic deformation during tensile and ratcheting behaviour of titanium.

\section{EXPERIMENTAL}

\section{Mechanical testing and microstructure characterisation}

old rolled and annealed plate of Grade 2 titanium with nominal chemical composition given in Table 1 was used. Flat specimens of dimension following ASTM Standard E606 [18] were machined from the as received plate with loading axis along 0,45 and 90 degree to RD. The schematic of specimen orientation and specimen dimension has been shown in Fig 1a and Fig. 1b respectively. All the experiments were conducted at room temperature using BiSS Nano Plug ' $n$ ' Play servo-hydraulic universal test machine of $25 \mathrm{KN}$ capacity. Tensile tests were carried out at constant strain rate of $5 \times 10^{-2} \mathrm{~s}^{-1}$ to obtain mechanical properties of the material. Engineering stress controlled uniaxial asymmetrical stress cycle was imposed on the specimens. Stress parameter used were stress amplitude/yield stress $\left(\sigma_{\mathrm{a}} / \sigma_{\mathrm{y}}=0.8\right)$ and mean stress/yield stress $\left(\sigma_{\mathrm{m}} / \sigma_{\mathrm{y}}=0.3\right)$. A sinusoidal waveform was used and cyclic frequency was kept at $0.5 \mathrm{~Hz}$ for all the tests. Tests were continued till failure and stress-strain data were acquired throughout the test for 200 data points per stress cycle. Tests were conducted under software control running on a computer interfaced to the control system of the testing machine. The sample designation for tensile and fatigue test has been listed in Table 2.

\begin{tabular}{llllll}
\hline Element $(\mathrm{wt} \%)$ & $\mathrm{Ti}$ & $\mathrm{Fe}$ & $\mathrm{O}$ & $\mathrm{C}$ & Rest \\
CP grade 2 $\mathrm{Ti}$ & 99.5 & 0.2 & 0.06 & 0.04 & 0.2 \\
\hline
\end{tabular}

Table 1: Chemical composition of as-received commercially pure titanium.

\begin{tabular}{llll}
\hline Loading condition & 0 degree & 45 degree & 90degree \\
Tensile & $0 \mathrm{~T}$ & $45 \mathrm{~T}$ & $90 \mathrm{~T}$ \\
Fatigue & OR & $45 \mathrm{R}$ & $90 \mathrm{R}$ \\
\hline
\end{tabular}

Table 2: Sample designation 
(a)

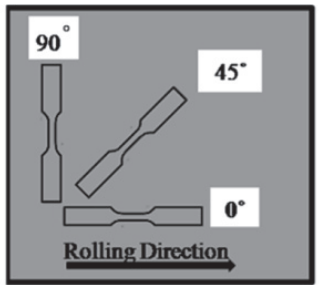

(b)

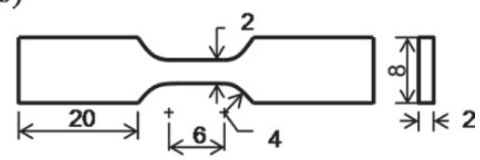

All dimensions are in $\mathrm{mm}$

Figure 1: a) Schematic of specimen orientation b) E606 specimen dimension.

\section{VPSC SIMULATION}

I

$\mathrm{n}$ order to predict the effect of texture on anisotropy in plastic deformation behavior of commercially pure titanium VPSC simulation was used. Viscoplastic self-consistent simulations were carried out using the viscoplastic selfconsistent code 7 (VPSC-7) package [19]. VPSC code is based on VPSC model to compute stress in grains and can incorporate hardening rules and texture information to simulate the stress- strain behaviour and deformation texture. The code models polycrystalline aggregates using single crystal constitutive law. This model also considers twinning mode of deformation. VPSC model considers each grain as a visco-plastic ellipsoidal inclusion embedded in a homogeneous effective medium (HEM). The plastic compliance of the aggregate is obtained by the Eshelby solution of deformation of ellipsoids through iterative scheme. The hardening response is based on updating the CRSS $\tau^{\alpha}$ following the constitutive power law that provides the shear strain rate $\dot{\gamma}^{\alpha}$ in each slip mode $\alpha$ based on the schmid factor $m^{\alpha}$ and a constant $\dot{\gamma}_{0}$ reflecting the macroscopic strain rate

$$
\dot{\gamma}^{\alpha}=\dot{\gamma}_{0}\left|\frac{m^{\alpha} \otimes \sigma}{\tau^{\alpha}}\right|^{n} \operatorname{sign}\left(m^{\alpha} \otimes \sigma\right)
$$

The shear stress with increase in strain is obtained using empirical voce hardening equation in order to simulate the stressstrain curve. In extended voce model, hardening of individual grains is given by

$$
\hat{\tau}_{s}=\tau_{0}^{s}+\left(\tau_{1}^{s}+\theta_{1}^{s} \Gamma\right)\left\{1-\exp \left(\begin{array}{c}
\theta_{0}^{s} \\
\tau_{1}^{s}
\end{array}\right)\right\}
$$

where the evolution of the CRSS for each slip system, $\mathrm{s}$, are represented by phenomenological parameters $\tau_{0}^{s}, \tau_{1}^{s}, \theta_{0}^{s}, \theta_{1}^{s}$ and $\Gamma$ is the accumulated shear strain in each grain, reflecting a curve fitting approach. The Voce hardening parameter used to generate simulated stress-strain curves are listed in Table 3. It is to be noted that the influence of contraction twin during deformation is very localized and could not be included in slip/twin list for von Mises stress calculation during simulation.

\begin{tabular}{ccccc}
\hline Slip/twin & $\tau_{0}$ & $\tau_{1}$ & $\Theta_{0}$ & $\Theta_{1}$ \\
Prismatic & 33 & 24 & 700 & 60 \\
Basal & 220 & 100 & 1100 & 100 \\
Pyramidal $<\mathrm{c}+\mathrm{a}>$ & 130 & 80 & 1000 & 2 \\
Extension twin & 90 & 5 & 10 & 5 \\
\hline
\end{tabular}

Table 3: Voce hardening parameter. 


\section{RESULTS AND DISCUSSION}

\section{Initial microstructure and texture}

7 he initial microstructure of the cold rolled and annealed plate of commercially pure titanium has equiaxed alpha grains with characteristic TD-split basal texture, as depicted from the inverse pole figure IPF-ND map and the 0002 pole figure contour plot represented in Fig. 2a and Fig. 2b, respectively. The tensile and ratcheting test specimen has fibre texture with crystallographic directions $\langle 10 \overline{1} 0\rangle-\langle 11 \overline{2} 0\rangle,\langle 10 \overline{1} 0\rangle$ and $\langle 11 \overline{2} 0\rangle$ alinged along the loading direction in case of 0,45 and 90 degree specimen, respectively as indicated from the contour plot of IPF-along loading axis shown in Fig. 2c.

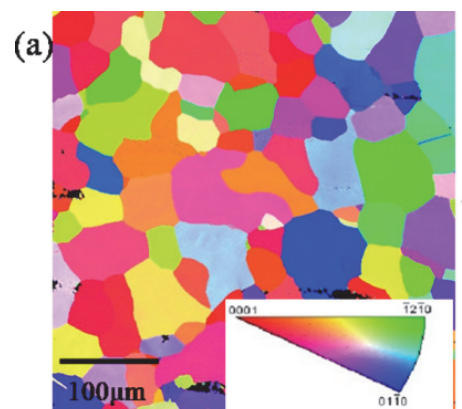

(c)

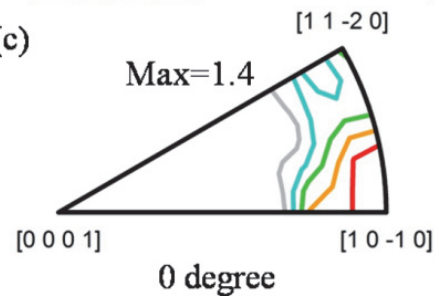

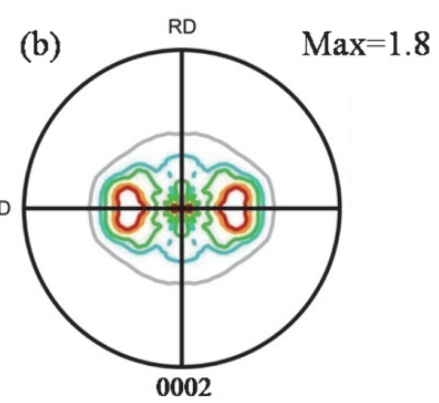

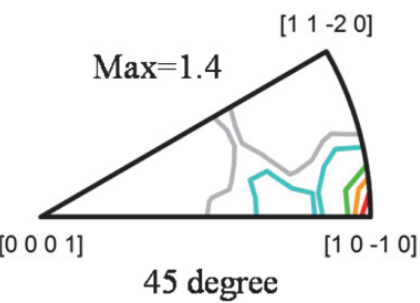

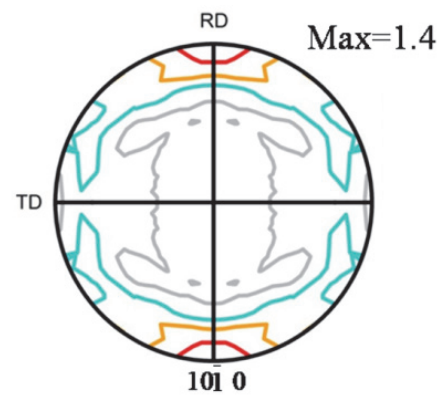

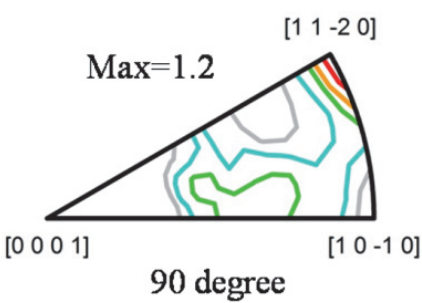

Figure 2: a) IPF-Z map showing equiaxed alpha grains in as received sheet b) 0002 and $10 \overline{1} 0$ pole figure and c) inverse pole figure plot for 0,45 and 90 degree orientation along the loading axis.

\section{TENSILE AND RATCHETING PROPERTY}

7 he variation of true stress vs true strain shown in Fig. 3a clearly indicates there is strong in-plane anisotropy in tensile properties. The corresponding yield strength, ultimate tensile strength (UTS) and the strain at UTS reported in Table 4 , indicates lower yield strength but higher ductility for $0 \mathrm{~T}$ sample whereas for $45 \mathrm{~T}$ and $90 \mathrm{~T}$ sample exactly opposite is true. On the other hand, the cyclic stress-strain plot, cyclic life and accumulated ratcheting strain shown in Fig. 3b, 3c and $3 \mathrm{~d}$, respectively indicates longer cyclic life for $0 \mathrm{R}$ sample but higher ratcheting strain for $90 \mathrm{R}$ sample. However, ratcheting strain for $45 \mathrm{R}$ sample has been found to be comparable to that of $0 \mathrm{R}$ sample. The observed anisotropy in tensile and ratcheting property could be understood from the orientation dependent slip/twin activity analysed using VPSC simulation and the results complimented with quantitative and qualitative characterisation of deformation microstructure using EBSD.

\begin{tabular}{lllllll}
\hline Mechanical Property & $0^{\circ}$ & Std Dev. & $45^{\circ}$ & Std Dev. & $90^{\circ}$ & Std Dev. \\
Yield strength (MPa) & 260 & 2.9 & 287 & 3.8 & 328 & 5.4 \\
Ultimate tensile strength (MPa) & 372 & 6.5 & 408 & 4.0 & 417 & 2.8 \\
Strain @ UTS & 0.30 & 0.09 & 0.13 & 0.05 & 0.19 & 0.02 \\
Number of cycles to failure & 2441 & 400 & 1585 & 250 & 1869 & 350 \\
Ratcheting strain & 0.15 & 0.02 & 0.16 & 0.009 & 0.26 & 0.004 \\
Misfit strain @ 1 1st cycle & 0.011 & - & 0.011 & - & 0.013 & - \\
\hline
\end{tabular}

Table 4: Tensile and ratcheting property 

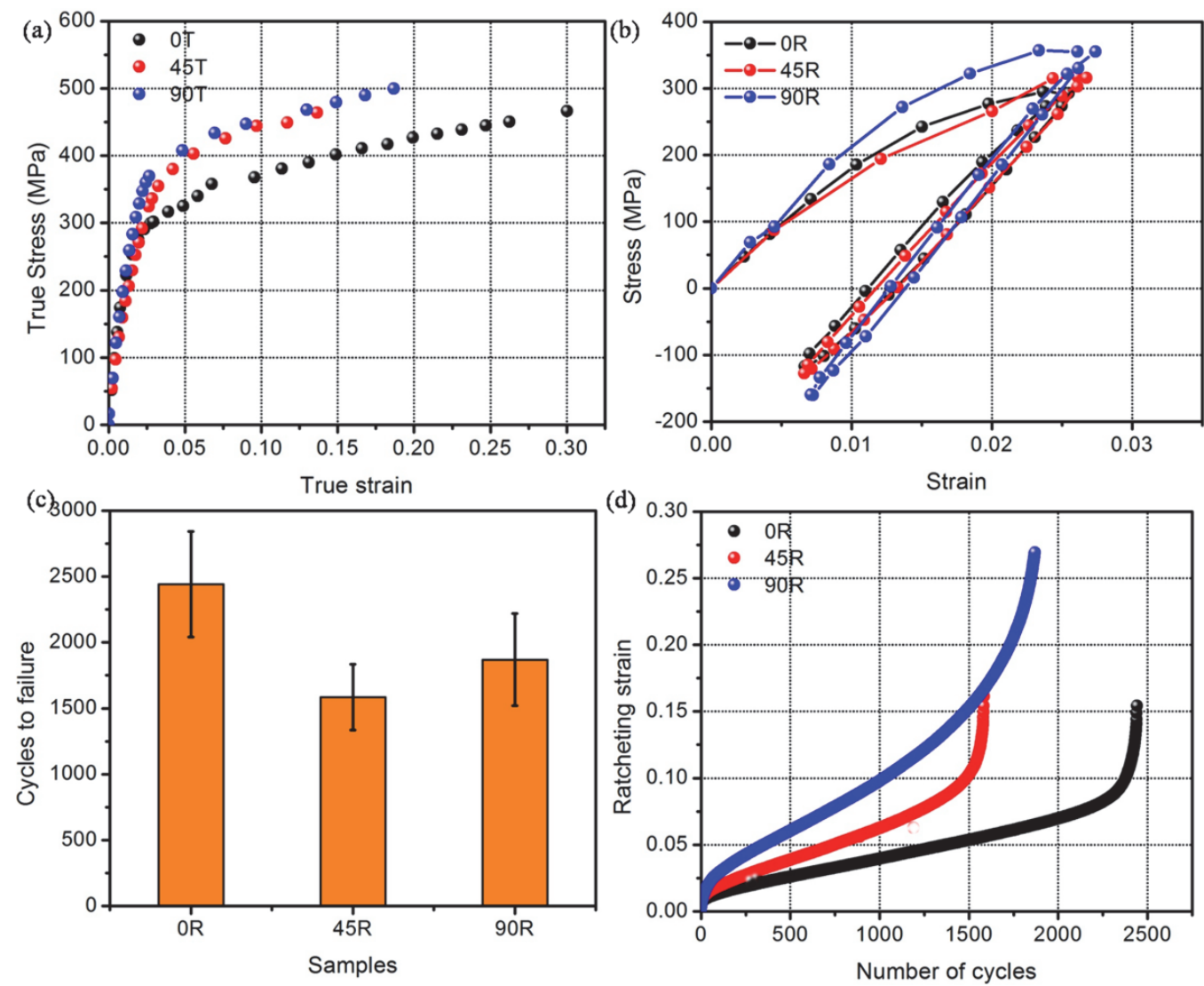

Figure 3: a) True stress-true strain curve b) Cyclic stress-strain curve of $1^{\text {st }}$ cycle c) Bar chart showing number of cycles to failure and d) Number of cycles to failure vs ratcheting strain.

\section{INFLUENCE OF ORIENTATION ON SLIP ACTIVITY}

he VPSC simulated stress-strain curve obtained using the voce hardening parameter reported in Table 3 follows similar hardening response as determined experimentally, shown in Fig. 4a. The relative slip/twin activity shown in Fig. $4 \mathrm{~b}$ indicates prism slip activity is higher while basal slip activity is lower in $0 \mathrm{~T}$ compared to $45 \mathrm{~T}$ and $90 \mathrm{~T}$ which is due to higher Schmid factor for primary prism slip $\{10 \overline{1} 0\}<11 \overline{2} 0>$ for $0 \mathrm{~T}$ orientation as indicated from the initial texture in Fig. 2c. Since, there is only two independent prism slip system, hence plastic deformation via slip is accompanied by twin activity also. However, with increase in strain, prism slip and extension twin activity decreases at a critical strain value of $\sim 0.16$ in $0 \mathrm{~T}$ which is slightly higher than that of $45 \mathrm{~T}$ and $90 \mathrm{~T}$ orientation. Beyond this crossover strain value, $<\mathrm{c}+\mathrm{a}>$ pyramidal slip activity rises. However, prism slip activity becomes constant and the increase in pyramidal slip is lower in $45 \mathrm{~T}$ compared to $90 \mathrm{~T}$. Thus, due to reduced slip activity at higher strain $45 \mathrm{~T}$ shows lower ductility and hence lower strain to failure compared to $90 \mathrm{~T}$. It is also clear that the activity of pyramidal slip with high critical resolved shear stress (CRSS) compared to prism slip is much higher in $90 \mathrm{~T}$ compared to 0T and 45T orientation, which results in lower strain hardening coefficient of 90T with high yield strength as reported in Table 4. However, observed relative slip activity from simulated stress-strain curves could not account well for the anisotropy in hardening response. Basically, commercially pure titanium exhibits three stage strain hardening behavior during tensile deformation [20]. First stage is purely slip dominated followed by twinning in the second stage and twin-slip dominated in the final stage of deformation. VPSC model is unable to estimate hardening response very accurately under the combined action of slip and twin activity, hence, very close match between the experimental and simulated hardening response could not be achieved. It is mainly due to orientation change and microstructural inhomogeneity issue especially associated with contraction twin activity. The influence of twin activity on anisotropic response would be depicted from the EBSD based microstructure and micro-texture analysis discussed in the next section. 

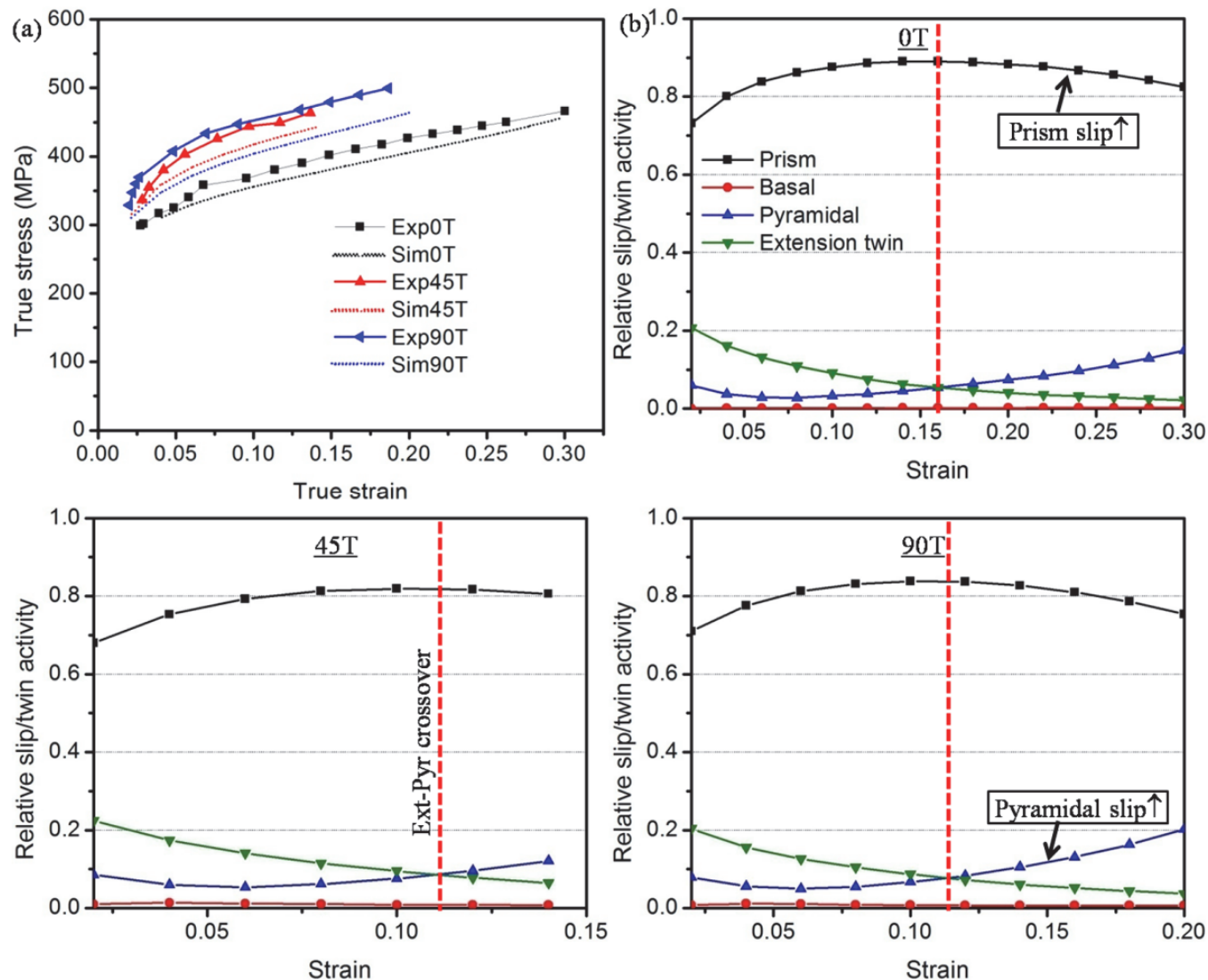

Figure 4: VPSC simulated stress- strain curve and b) Relative slip/twin activity for tensile samples.

\section{ROLE OF TWINS IN ANISOTROPIC TENSILE DEFORMATION BEHAVIOUR}

$\mathrm{T}$

he observed anisotropy in strain hardening response during tensile deformation could be understood from the characterisation of deformation twins, using the crystal orientation map shown in Fig. 5a. The deformation microstructure shows grains with $\langle 0001\rangle \| N D$ basal orientations, which are twin free in all the three samples. In CP-Titanium off-basal and non-basal orientations are more prone to twinning while $\langle 0001\rangle \| \mathrm{ND}$ orientations are twin free and exhibit higher hardness [21]. Both contraction twin (CT) and extension twins (ET) are formed as indicated from the grain boundary misorientation plot in Fig. 5b. Sample 0T shows almost equal volume fraction of contraction and extension twin $(5.8 \% \mathrm{CT}+5 \% \mathrm{ET})$ whereas sample $45 \mathrm{~T}(2.6 \% \mathrm{CT}+6.5 \% \mathrm{ET})$ and $90 \mathrm{~T}(3.8 \% \mathrm{CT}+8.6 \% \mathrm{ET})$ has higher volume fraction of extension twin. In addition, the morphology and twin variants have been found to be distinctly different in $0 \mathrm{~T}$, $45 \mathrm{~T}$ and $90 \mathrm{~T}$. The characterisation of twins in two different parent grain orientations: near basal and off basal shown in Fig. 6 reveals, in $0 \mathrm{~T}$ sample both the orientations have thin contraction twins with extension twins present inside contraction twins and the contraction twins are multi-variant in nature as indicated from the unfolded IPF-loading axis contour plot. On the other hand, in $45 \mathrm{~T}$ and $90 \mathrm{~T}$ sample, twins are relatively thicker than in $0 \mathrm{~T}$ sample and the extension twins are more prevalent in off basal grain orientation whereas contraction twins are present in near basal grain orientation. Moreover, in $45 \mathrm{~T}$ sample parallel arrays of single twin variant has been observed while in $90 \mathrm{~T}$ sample, intersecting twins of multi-variant nature are present. Thus, due to higher prism slip activity dislocation glide through forest dislocation becomes difficult, when deformation proceeds by formation of high volume fraction of thin, intersecting, multi-variant contraction twins, leading to higher strain hardening of $0 \mathrm{~T}$ compared to $45 \mathrm{~T}$ and $90 \mathrm{~T}$. This also suppresses the activation of pyramidal slip for higher strain and increases ductility in $0 \mathrm{~T}$. On the other hand, in $45 \mathrm{~T}$ and $90 \mathrm{~T}$ deformation can proceed easily by lateral thickening of extension twins leading to lower strain hardening coefficient, which could be attributed to less elastic stiffness difference between the parent grain matrix and the twinned region as proposed by Sinha et al. [15]. In addition, twinned region gets reoriented to unfavourable prism slip orientation which suppresses prism slip activity. The deformation along c-axis is accommodated by harder $<\mathrm{c}+\mathrm{a}>$ pyramidal slip which reduces tensile ductility in $45 \mathrm{~T}$ and $90 \mathrm{~T}$. 

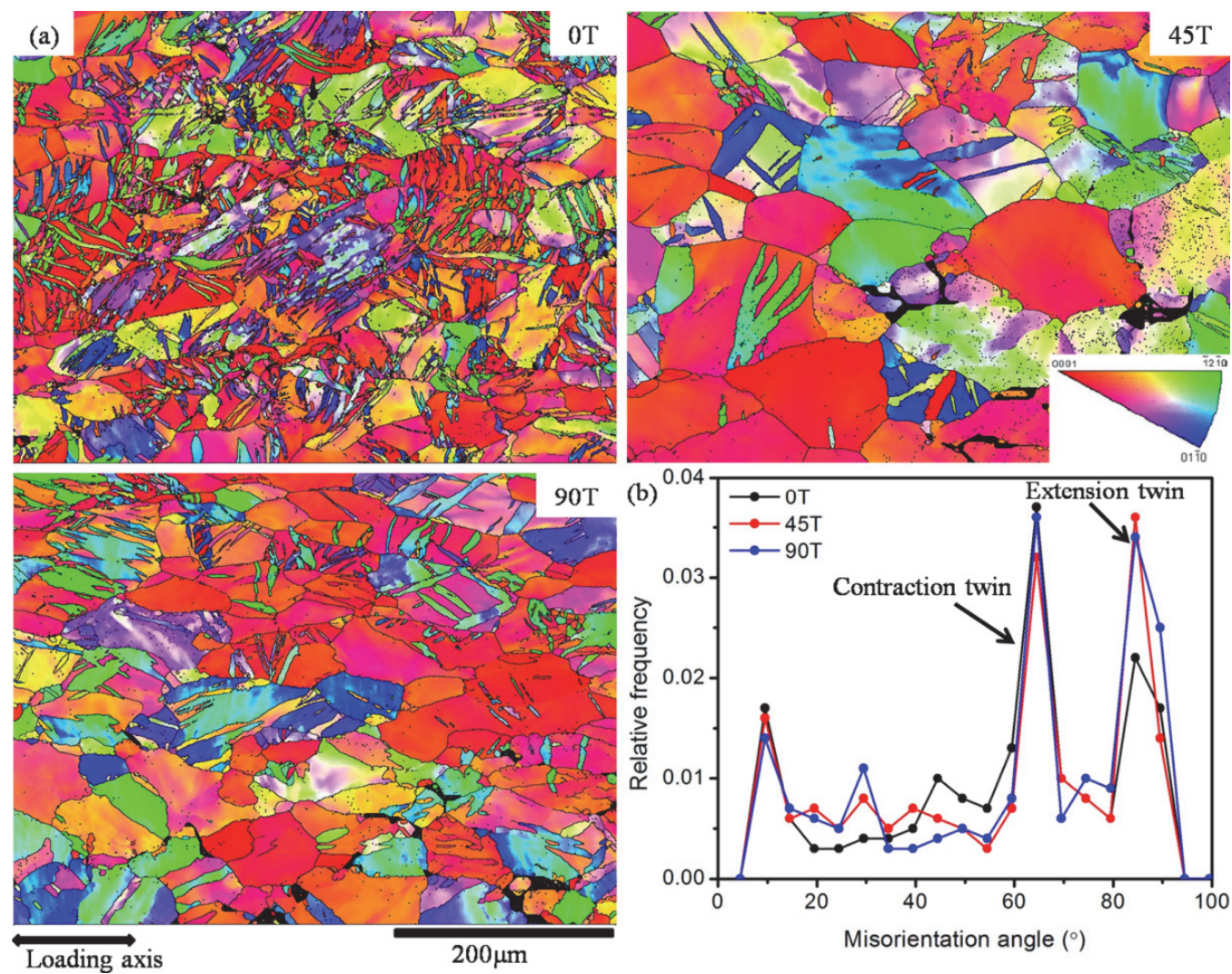

Figure 5: a) Crystal orientation map showing deformation microstructure and b) Grain boundary misorientation angle distribution showing fraction of contraction and extension twins in tensile specimen.

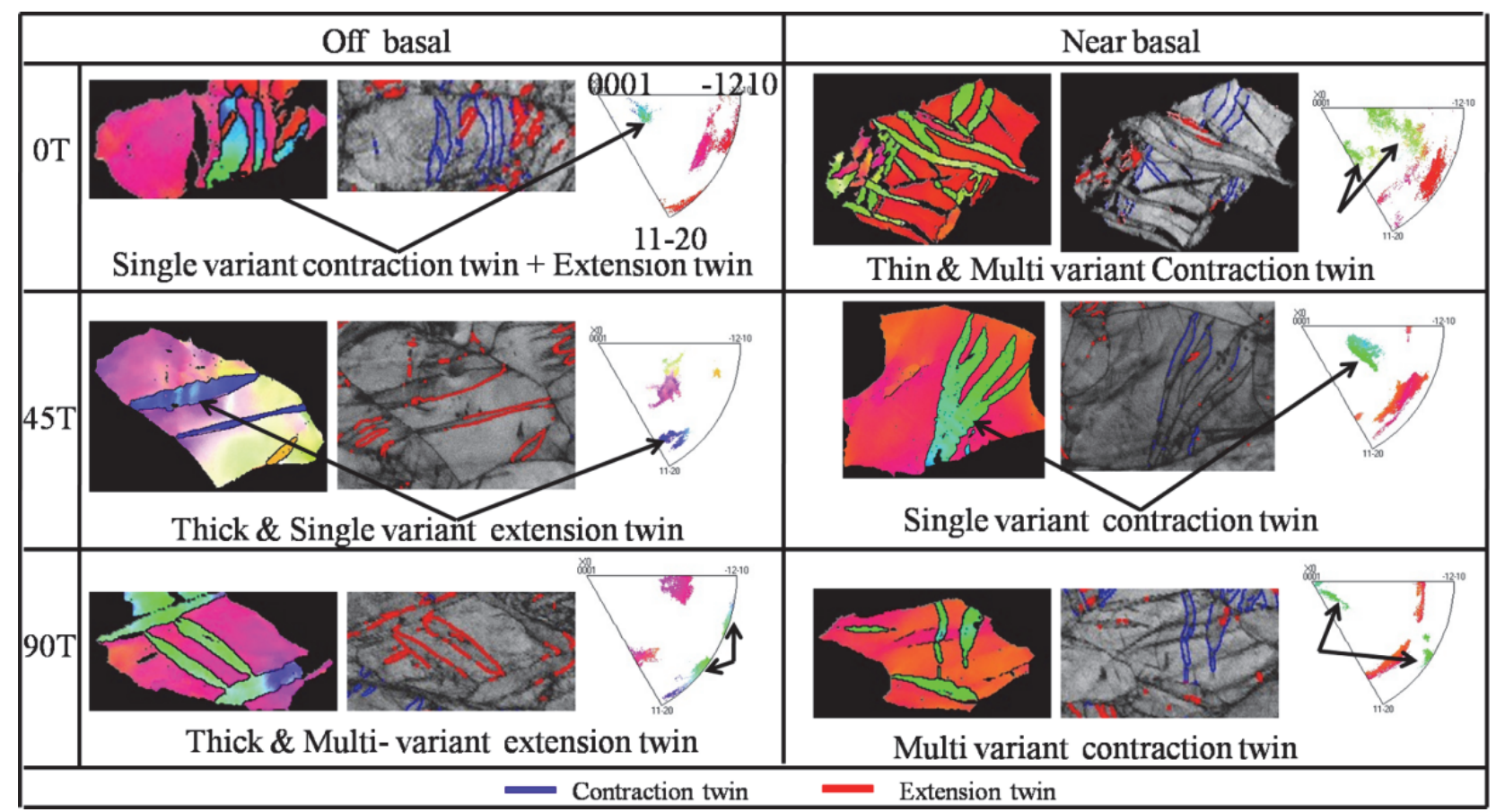

Figure 6: Crystal orientation map, IPF-loading axis and band contrast map delineated with contraction twins (blue lines) and extension twins (red lines) showing the morphology and orientation of twins for two different grain orientation of tensile sample. 


\section{CORRELATION BETWEEN TENSILE AND RATCHETING PROPERTY}

he strength-ductility property of commercially pure titanium as a function of orientation of the loading direction $(0 \rightarrow 45 \rightarrow 90$ degree $)$ during monotonic tensile loading gets manifested in different way during cyclic loading. This is evident from the comparision of different tensile and ratcheting properties shown in Fig. 7. Fig. 7a shows orientation in which strain hardening coefficient is high, ratcheting life is low. Interestingly, ratcheting strain and tensile strain to failure are inversely related, however, the increase in ratcheting strain for 45 degree orientation is much lower compared to 90 degree orientation as indicated by red dotted circle in Fig. 7b. Basically, ratcheting is a phenomenon which occurs during stress controlled cyclic loading when the cross slip activity is promoted by internal stresses generated in the material [22]. The internal stresses arise from dislocation substructures formation and which obviously depends on the slip/twin activity. However, in order to understand the correlation between tensile and ratcheting property, the manifestation of slip/twin system as a function of orientation influencing cyclic deformation in each tension-compression cycle is required and has been predicted using VPSC simulation.

(a)

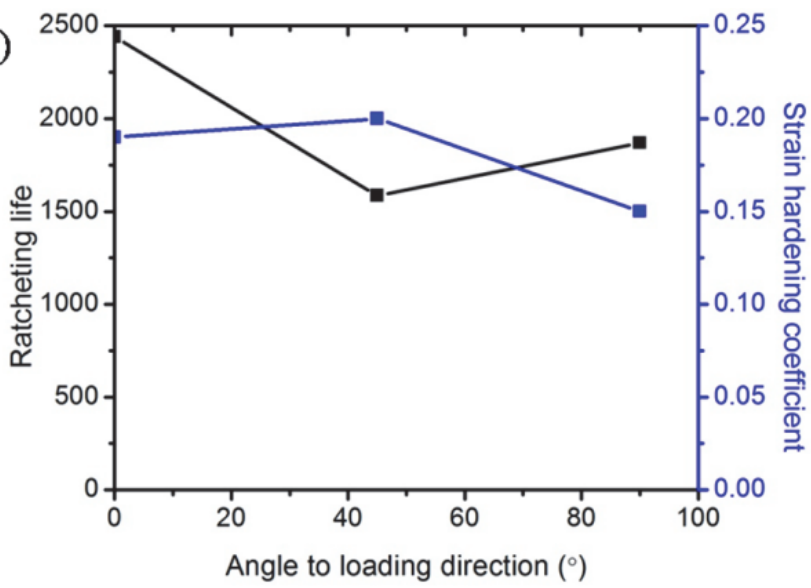

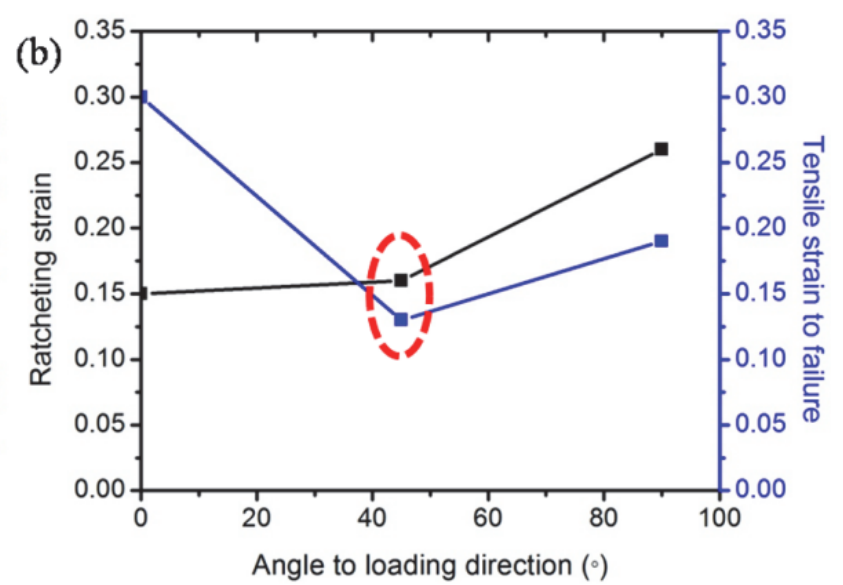

Figure 7: Variation of a) ratcheting life and strain hardening coefficient and b) Ratcheting strain and tensile strain to failure with respect to loading direction.

During ratcheting the cumulative accumulation of strain proceeds in three stages- initial stage of slow rate of increase in ratcheting strain, followed by constant rate of increase in ratcheting strain and finally rapid rate of increase in ratcheting strain leading to failure as indicated in Fig. 3d. The yield locus for the $1^{\text {st }}$ cycle tension-compression-reload tension shown in Fig. 8a depicts contraction of yield surface continuously with each compression and reload-tension half cycle w.r.t the initial tension half cycle in $0 \mathrm{R}$ and $90 \mathrm{R}$ orientation. On the other hand, in $45 \mathrm{R}$ orientation yield surface expands w.r.t the initial tension half cycle during compression half cycle and reload tension half cycle. It is because the average number of active slip system in the tension half cycle is higher in $0 \mathrm{R}$ compared to $45 \mathrm{R}$ and $90 \mathrm{R}$, while the trend is opposite in compression and reload tension half cycle as indicated from Fig. 8b. The increase in average number of slip system in $0 \mathrm{R}$ is mainly due to prism slip while in $45 \mathrm{R}$ and $90 \mathrm{R}$, is due to increase in basal slip, pyramidal slip. The pyramidal slip activity is slightly higher in 45R compared to 90R leading to higher yield locus during reload tension of 45R. Another interesting observation is the detwinning of extension twin during compression half cycle as predicted from VPSC simulation shown in Fig. 9. The alternating activity of extension twin and pyramidal slip between tension-compression cycle has also been shown by Elasto-plastic self consistent (EPSC) simulation during strain controlled cyclic deformation of CP-Titanium [17]. The reason behind lower extension twin activity during compression half cycle has been attributed to detwinning of extension twin because of backstress generated during forward loading. Thus, due to higher prism slip activity and suppressed pyramidal slip activity during compression half cycle, $0 \mathrm{R}$ exhibits longer life compared to 45R and 90R. However, the predicted slip/twin activity could not explain the reason behind lower ratcheting strain of $45 \mathrm{R}$, which needs analysis of the role of twinning interpreted from EBSD analysis of deformation microstructure. 


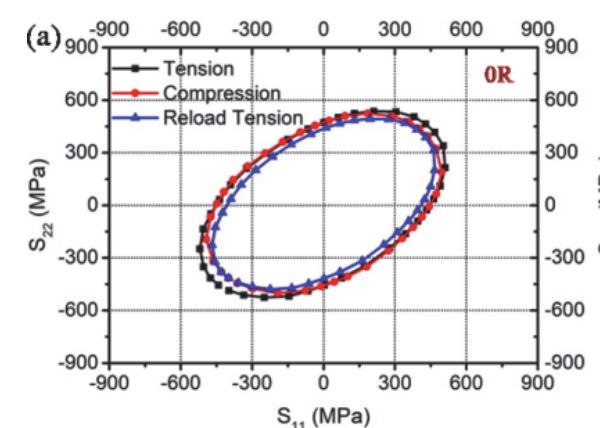

(b) Tension

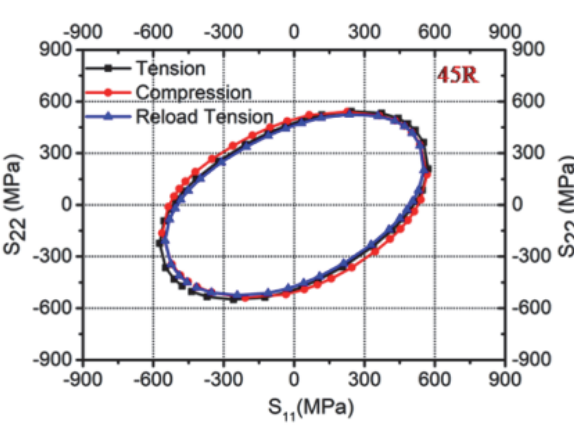

Compression

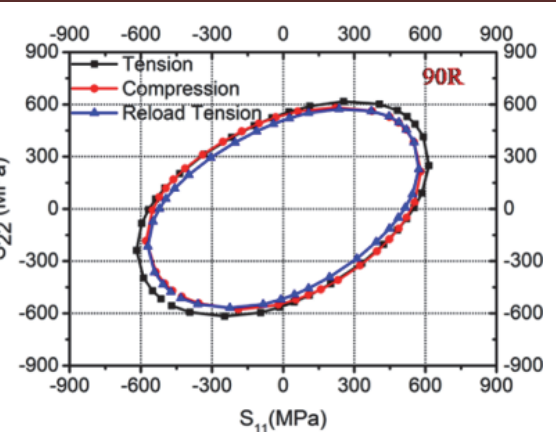

Reload tension

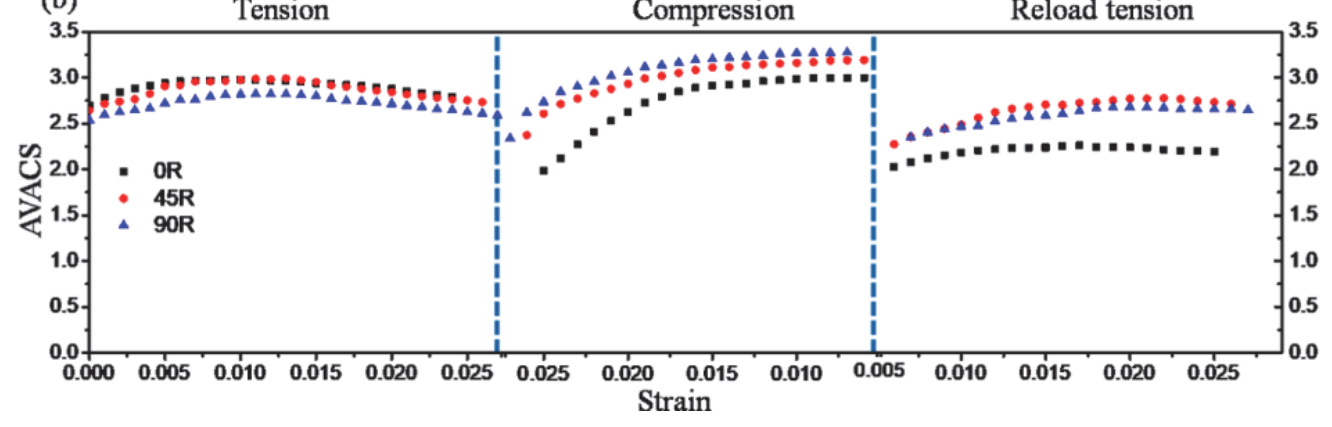

Figure 8: a) Yield locus and b) average number of active slip system (AVACS) for $1^{\text {st }}$ cycle of tension-compression-reload tension
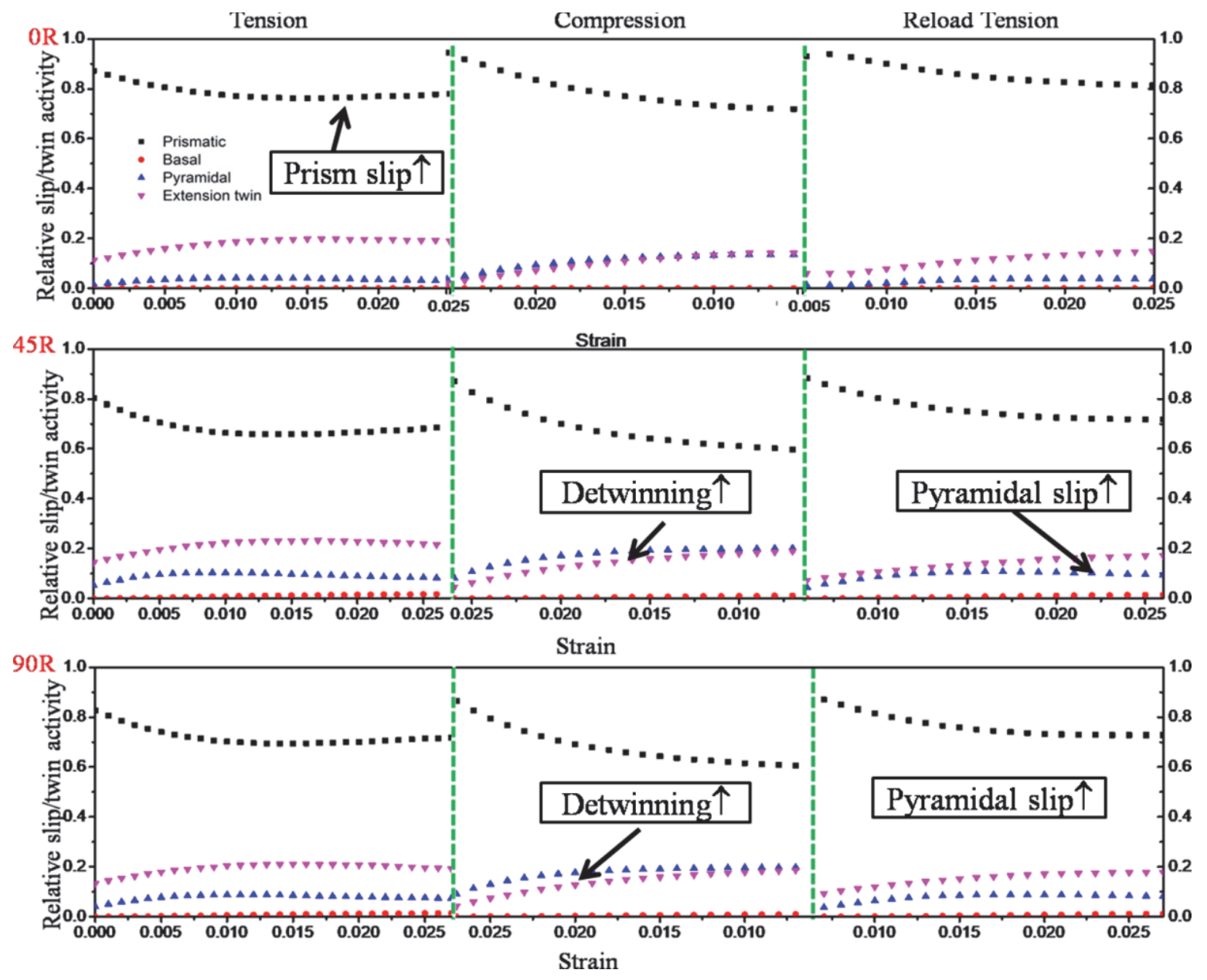

Figure 9: Slip/twin activity for $1^{\text {st }}$ cycle of tension-compression-reload tension. 


\section{ORIENTATION SPECIFIC DAMAGE EVOLUTION DURING FATIGUE}

$\mathrm{T}$ he deformation microstructure of ratcheting samples show much lower volume fraction of twins due to lower applied stress as compared to tensile samples as depicted from the crystal orientation map along ND shown in Fig. 10a. Twins has been found to be prevalent in basal (B) grains $(<0001>\| N D)$ and non-basal (NB) grains $(<11 \overline{2}$ $0>\| N D)$, while non-basal grains $(<10 \overline{1} 0>\| N D)$ are mostly twin free in all the three orientations. The characteristic feature of twin morphology and their nature could be interpreted from the band contrast maps delineated with contraction twin (blue lines) and extension twin boundaries (red line) shown in Fig. 10b. The volume fraction of contraction twin has been found to be higher compared to extension twin for $0 \mathrm{R}$ from Table 5. In addition, the extension twins has been found to be confined within the contraction twin as observed from Fig. 10a. Thus, extension twins are unable to reorient the parent grain orientation unfavourable for prism slip, which keeps prism slip activity high during tensile half cycle leading to slow rate of steady state creep and lower ratcheting strain accumulation. While in 45R and 90R, the volume fraction of extension twins has been found to be higher compared to contraction twins from Table 5. As indicated from Fig. 9, extension twins are formed during tensile half cycle and detwinning promote basal and pyramidal slip activity in subsequent compression and reload tension half cycle. Moreover, due to increased basal slip and pyramidal slip activity in 45R and 90R sample, cross slip becomes easy which causes rapid accumulation of higher ratcheting strain.

From the above discussion it is apparent that in orientation 0R with high Schmid factor for prism slip, deformation proceeds via prism slip and formation of multi-variant contraction twins. In titanium due to low stacking fault energy of prism plane, prism slip on this plane leads to formation of twins readily [23]. Contraction twins require higher stress to nucleate and hence of dislocation pile ups are the potential nucleation site for contraction twins [13]. However, the amount of stored dislocation density in tensile specimen is much higher compared to ratcheting specimen [24]. This is due to the formation of dislocation pile up and tangles during tensile deformation while stable dislocation configuration like well organized dislocation cell structure forms during cyclic deformation. The cell walls are regions accommodating high density of dislocations surrounding dislocation free zones. The high value of low angle grain boundary (LAGB) fraction of 0R sample compared to $45 \mathrm{R}$ and $90 \mathrm{R}$ from Table 5 indicates formation of dislocation cell structures in $0 \mathrm{R}$ sample. Thus, cell walls could be the nucleation site for contraction twin, which helps in reducing backstress in the grain matrix during cyclic deformation. The grain boundary misorientation parameter in terms of local average misorientation angle (LAM) and grain reference orientation deviation (GROD) reported in Table 5 gives indirect measure of local and global deformation of grains. Hence, higher LAM and GROD value of sample 45R and 90R sample indicates higher overall grain deformation in $45 \mathrm{R}$ and $90 \mathrm{R}$ compared to $0 \mathrm{R}$. This is due to activation of cross slip which is more feasible in orientation less favourable for primary slip system i.e, prism slip as in 45R and 90R. Similar observation has been reported in cross rolled and annealed commercially pure titanium with RD- split basal texture and hence more prone to cross slip along TD orientation [25]. The amount and rate of ratcheting strain accumulation depends on the competition between strain hardening due to primary slip and twinning and the dynamic recovery via activation of cross slip. As 45 degree orientation has strain hardening coefficient comparable to 0 degree thus $45 \mathrm{R}$ is less prone to cross slip and hence accumulates less ratcheting strain than expected. Cross slip activity dominates cyclic deformation with decrease in available primary slip/twin systems, which reduces geometrically necessary dislocation (GND) density required for strain compatibility between adjacent dislocation cell boundaries. The GND density map shown in Fig. 10c indicates that in $0 R$ and $90 \mathrm{R}$ sample GND density is high in twin free non-basal grains compared to twinned basal grains while in 45R sample, GND density is concentrated at the grain boundaries while the grain matrix has lower GND density. This makes the crack propagation path more feasible along the grain boundaries for 45R. It is clear from the fracture surface feature at the stable fatigue crack growth region of $0 \mathrm{R}$ and 45R sample shown in Fig. 11. It shows that in $0 \mathrm{R}$ sample there are small pockets of differently oriented shallow striation marks indicating crack propagation in zig-zag path along the intersecting twin boundaries leading to higher crack propagation resistance and hence higher fatigue life of $0 \mathrm{R}$. Whereas, in 45R sample due to high GND density at the grain boundaries, cracks nucleate and propagate easily along the grain boundaries forming tearing ridges while within the grain matrix, parallel arrays of shallow striation marks are present due to low GND density, thus leading to lower fatigue life of $45 \mathrm{R}$

\begin{tabular}{lllllllll}
\hline Sample & $\begin{array}{l}\text { \%VLAGB } \\
\left(2-5^{\circ}\right)\end{array}$ & $\begin{array}{l}\text { \%LAGB } \\
\left(5-15^{\circ}\right)\end{array}$ & $\begin{array}{l}\text { \%HAGB } \\
\left(>15^{\circ}\right)\end{array}$ & \%ET & $\% \mathrm{CT}$ & $\begin{array}{l}\text { Total } \\
\text { twin }(\%)\end{array}$ & $\begin{array}{l}\text { LAM } \\
\left({ }^{\circ}\right)\end{array}$ & $\begin{array}{l}\text { GROD } \\
\left({ }^{\circ}\right)\end{array}$ \\
0R & 0.78 & 3.12 & 85.99 & 0.89 & 4.84 & 5.73 & 0.48 & 0.058 \\
$45 \mathrm{R}$ & 0.14 & 0.89 & 98.95 & 4.41 & 0.82 & 5.23 & 3.01 & 3.72 \\
$90 \mathrm{R}$ & 0.01 & 0.10 & 99.89 & 3.60 & 0.52 & 4.12 & 0.75 & 1.24 \\
\hline
\end{tabular}

Table 5: Grain boundary misorientation characteristics of fatigue samples 
(a)
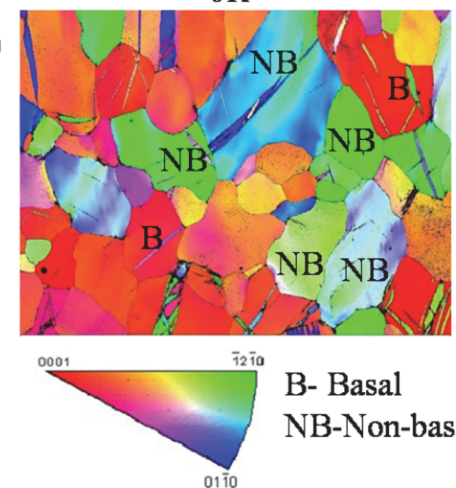

B- Basal NB-Non-basal

b)

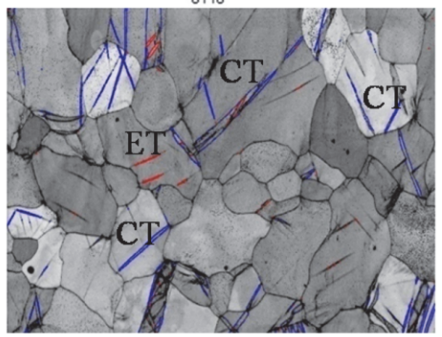

(c)

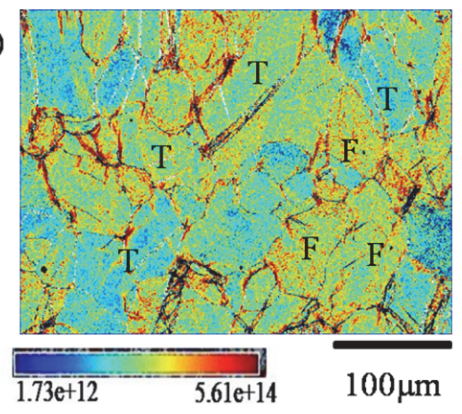

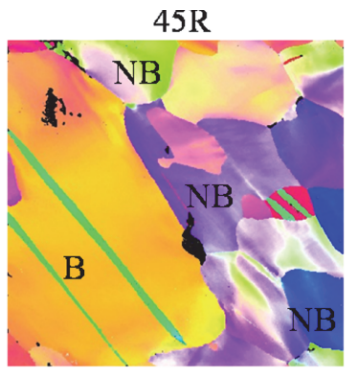

T- Twinned grain F-Twin free grain
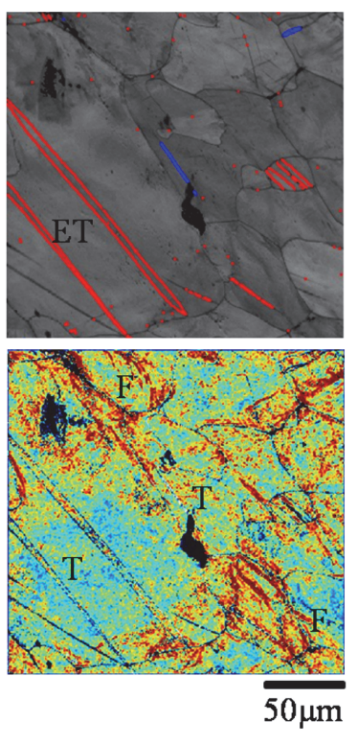

$90 \mathrm{R}$

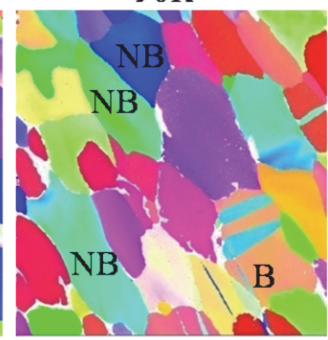

Contraction twin

Extension twin
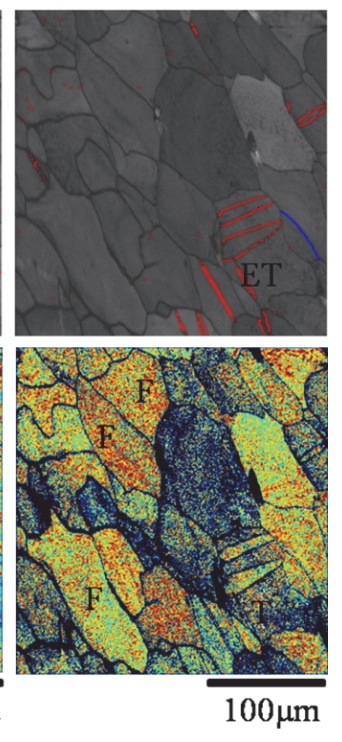

Figure 10: a) Crystal orientation map b) band contrast map delineated with contraction twin (blue lines) and extension twins (red lines) and c) GND density map of ratcheting samples.

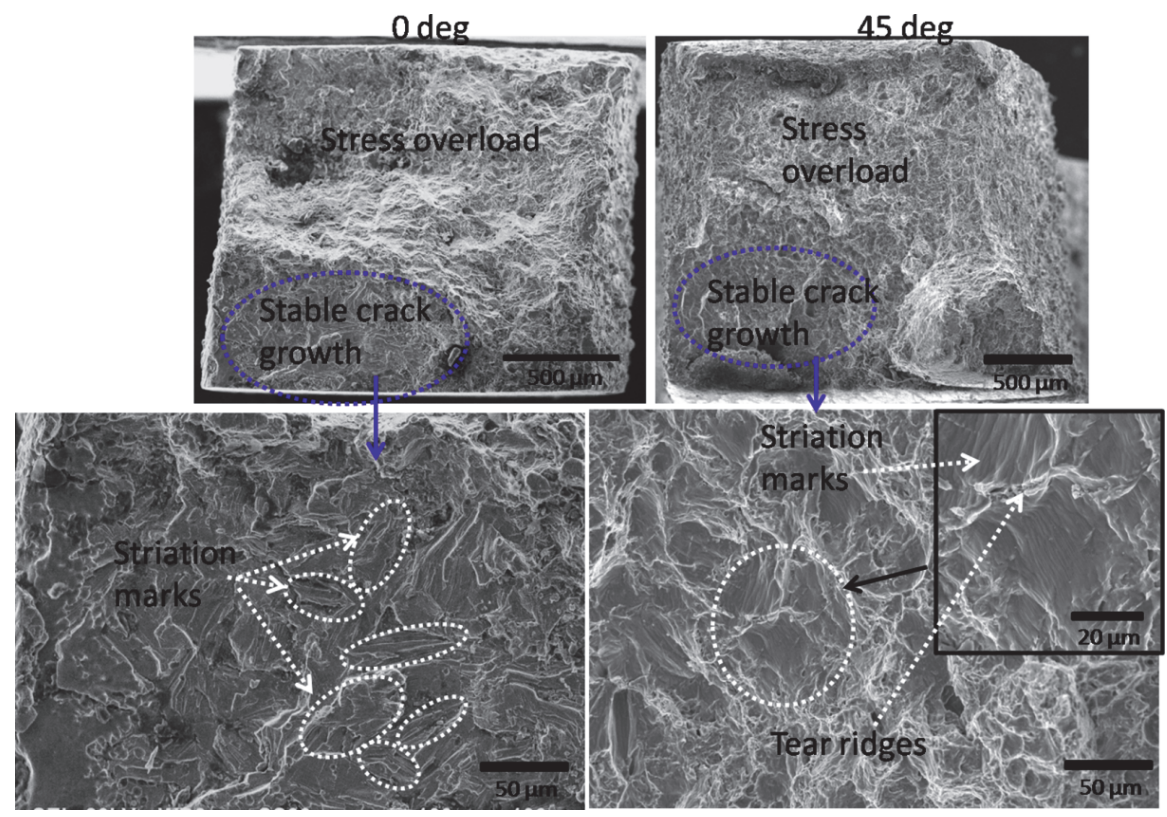

Figure 11: SEM fractograph of ratcheting sample for a) 0 degree and b) 45 degree orientation showing magnified image of striation marks (inset). 
As indicated from the fracture surface the material exhibit fatigue crack propagation via appreciable amount of plastic deformation of the matrix and hence fracture analysis can be carried out in the elastic-plastic regime. Accordingly, the numerically calculated crack nucleation time $\left(t_{n}\right)$ and damage evolution (D) following the relation given in [26] and [27], respectively has been plotted in Fig. 12. It shows that as the orientation of the loading axis changes from 0 to 90 degree the Schmid factor for primary slip system i.e, prism slip decreases and with decrease in Schmid factor the fatigue crack nucleation time increases. While the damage evolution rate due to nucleated crack has been found to be comparable in 45 and 90 degree orientation, hence, $90 \mathrm{R}$ sample showed higher ratcheting strain to failure compared to $45 \mathrm{R}$ sample.
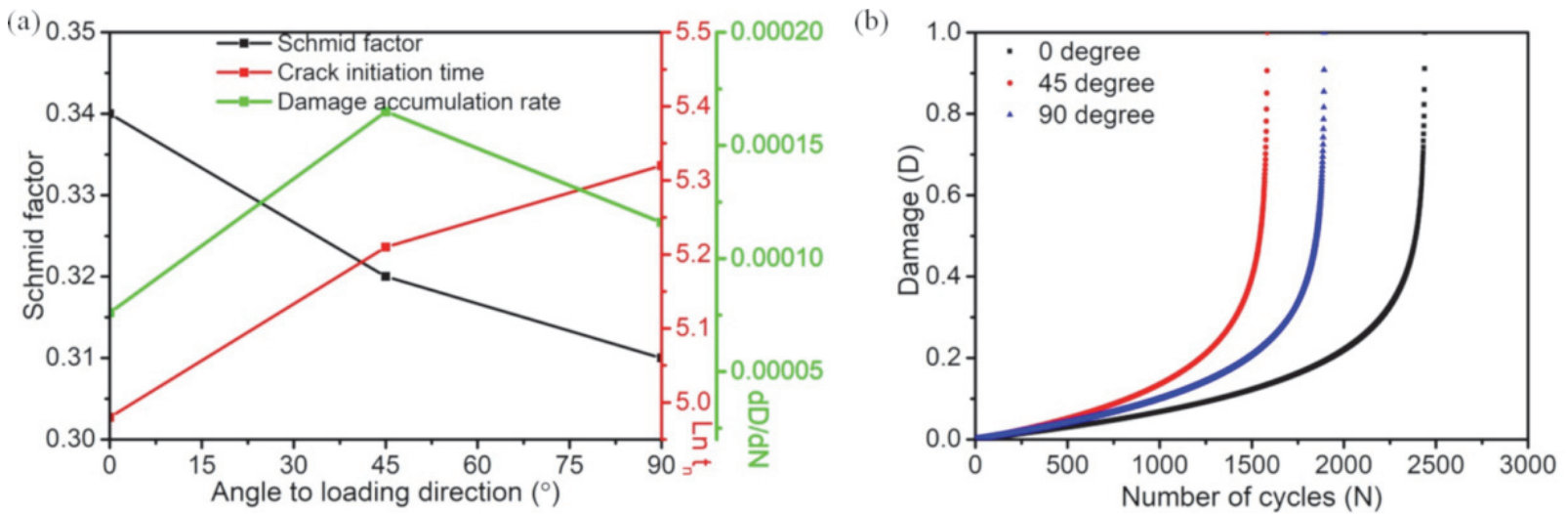

Figure 12: a) Schmid factor of prism slip, crack initiation time and damage accumulation rate plotted against loading direction and b) Damage evolution curve.

\section{CONCLUSIONS}

7 he present investigation leads to following conclusions:

1) As the orientation of the loading direction of basal grains change from $\langle 10 \overline{1} 0\rangle$ in 0 degree to $\langle 11 \overline{2} 0\rangle$ in 90 degree, deformation mechanism changes from predominant prism + contraction twin activity to extension twin + pyramidal slip activity leading to higher yield strength and tensile strength but poor fatigue life of 90 degree sample compared to 0 degree sample.

2) During cyclic deformation in 0R orientation continuous contraction of yield surface indicates cyclic softening due to high prism slip and contraction twin activity leads to longer fatigue life in 0R orientation. While, in 45R, there is expansion of yield surface due to reduced prism slip activity and due to extensive detwinning of extension twins during compression half cycle but induced cross slip in 90R contributes to higher cumulative strain accumulation in 90R.

\section{ACKNOWLEDGEMENTS}

7 he author would like to thank Department of Science and Technology, Government of India for funding this work through INSPIRE fellowship of Atasi Ghosh (research grant no. DST/INSPIRE/04/2016/001217). The author would like to thank Dr. Subhasis Sinha, postdoctoral fellow and Prof. Nilesh Gurao, Associate professor at IIT

Kanpur for providing their help in manuscript preparation. The author also thanks the imaging facility available in ACMS at IIT Kanpur for carrying out the microstructure characterization successfully.

\section{REFERENCES}

[1] Kuruvilla, M., Srivatsan, T.S., Petraroli, M., Park, L. (2008). An investigation of microstructure, hardness, tensile behavior of a titanium alloy: role of orientation, Sadhana, 33(3), pp. 235-250. DOI: 10.1007/s12046-008-0017-2.

[2] Li, H., Mason, D.E., Yang, Y., Bieler, T.R., Crimp, M.A. and Boehlert, C.J. (2013). Comparison of the deformation behaviour of commercially pure titanium and Ti-5Al-2.5Sn (wt. \%) at 296 and $728 \mathrm{~K}$, Phil. Mag. 93 (21), pp. 28752895. DOI: $10.1080 / 14786435.2013 .791752$. 
[3] Sinha, S., Ghosh, A. and Gurao, N.P. (2016). Effect of initial orientation on the tensile properties of commercially pure titanium, Phil. Mag. 96 (15), pp. 1485-1508. DOI: 10.1080/14786435.2016.1165873.

[4] Roth, A., Lebyodkin, M.A., Lebedkina, T.A, Lecomte, J.S, Richeton, T. and Amouzou, K.E.K. (2014). Mechanisms of anisotropy of mechanical properties of $\alpha$-titanium in tension conditions, Mater. Sci. Eng. A, 596 (24), pp. $236-243$. DOI: $10.1016 /$ j.msea.2013.12.061.

[5] Srinivasan, N., Velmurugan, R., Kumar, R., Singh, S.K., and Pant, B. (2016). Deformation behavior of commercially pure (CP) titanium under equi-biaxial tension, Mater. Sci. Eng. A, 674 (30), pp. 540-551.

DOI: $10.1016 /$ j.msea.2016.08.018

[6] Bathini, U., Srivatsan, T.S., Patnaik, A.K., and Menzemer, C. (2011). Mechanisms Governing Fatigue, Damage, and Fracture of Commercially Pure Titanium for Viable Aerospace Applications, J. Aerosp. Eng., 24 (4), pp. $415-424$. DOI: 10.1061/(ASCE)AS.1943-5525.0000090.

[7] Barkia,B., Doquet, V., Couzinie', J.P., Guillot, I., and He'ripre', E. (2015). In situ monitoring of the deformation mechanisms in titanium with different oxygen contents, Mater. Sci. Eng. 636 (11), pp. 91-102.

DOI: $10.1016 /$ j.msea.2015.03.044.

[8] Won, J.W., Park, K.T., Hong, S.G., and Lee, C.S. (2015). Anisotropic yielding behavior of rolling textured high purity titanium, Mater. Sci. Eng. A, 637 (18), pp. 215-221. DOI: 10.1016/j.msea.2015.03.096.

[9] Hama,T., Nagao, H., Kobuki, A., Fujimoto, H., and Takuda, H. (2015). Work-hardening and twinning behaviors in a commercially pure titanium sheet under various loading paths, Mater. Sci. Eng. A, 620 (3), pp. 390-398. DOI: $10.1016 /$ j.msea.2014.10.024.

[10] Nixon, M.E., Cazacu, O., and Lebensohn, R.A. (2010). Anisotropic response of high-purity $\alpha$-titanium: Experimental characterization and constitutive modeling, Int. J. Plasticity, 26 (4), pp. 516-532. DOI: 10.1016/j.ijplas.2009.08.007.

[11] Valle, E.C.M, Pachla, V., Kulczyk, M., Savoini, B., Monge, M.A., Ballesteros, C., and Sabirov, I. (2013). Anisotropy of uni-axial and bi-axial deformation behavior of pure Titanium after hydrostatic extrusion, Mater. Sci. Eng. A, 588 (20), pp. 7-13. DOI: 10.1016/j.msea.2013.08.044.

[12] Wang, L., Zhang, H., Huang, G., Cao, M., Cao, X., Mostaed, E., and Vedani, M. (2016). Formability and anisotropy of the mechanical properties in commercially pure titanium after various routes normal and different speed rolling, J. Mater. Res., 31 (21), pp. 3372-3380. DOI: 10.1557/jmr.2016.352.

[13] Christian, J.W. and Mahajan, S. (1995). Deformation twinning, Progr. Mater. Sci., 39 (1-2), pp. 1-157. DOI: 10.1016/0079-6425(94)00007-7.

[14] Arul Kumar, M., Kanjarla, A.K., Niezgoda, S.R., Lebensohn, R.A., and Tome, C.N. (2015). Numerical study of the stress state of a deformation twin in magnesium, Acta Mater., 84 (1), pp. 349-358. DOI:10.1016/j.actamat.2014.10.048.

[15] Sinha, S., Pukenas, A., Ghosh, A., Singh, A., Skrotzki, W., and Gurao, N.P. (2017). Effect of initial orientation on twinning in commercially pure titanium, Phil. Mag., 97 (10), pp. 775-797. DOI: 10.1080/14786435.2017.1279364.

[16] Ghosh, A., and Gurao, N.P. (2017). Effect of crystallographic texture on ratcheting response of commercially pure titanium, Mater. Des., 115 (5), pp. 121-132. DOI: 10.1016/j.matdes.2016.11.052.

[17] Sinha, S., and Gurao, N.P. (2017). In-Plane Anisotropy in Mechanical Behavior and Microstructural Evolution of Commercially Pure Titanium in Tensile and Cyclic Loading, Metall. Mater. Trans. A 48 (12), pp. 5813-5832.

DOI: $10.1007 /$ s11661-017-4349-6.

[18] ASTM E-606-80, Standard Recommended Practice for Constant Amplitude Low Cycle Fatigue Testing, 100 Barr Harbor Drive, PO Box C700, West Conshohocken, PA 19428-2959, United States; 2016.

[19] Lebensohn, R.A., Tome, C.N. (1993). A self - consistent anisotropic approach for the simulation of plastic deformation and texture development of polycrystals: application to zirconium alloys, Acta metall. Mater. 41(9), pp. 2611-2624. DOI:10.1016/0956-7151(93)90130-K.

[20] Becker, H. and Pantleon, W. (2013). Work-hardening stages and deformation mechanism maps during tensile deformation of commercially pure titanium, Comp. Mater. Sci., 76, pp. 52-59. DOI: 10.1016/j.commatsci.2013.03.028.

[21] Panda, S., Sahoo, S.K., Dash, A., Bagwan, M., Kumar, G., Mishra, S.C., and Suwas, S. (2014). Orientation dependent mechanical properties of commercially pure (cp) titanium, Mater. Charact. 98, pp. 93-101.

DOI: $10.1016 /$ j.matchar.2014.10.011.

[22] Gaudin, C., and Feaugas, X. (2004). Cyclic creep process in AISI 316L stainless steel in terms of dislocation patterns and internal stresses, Acta Mater. 52 (10), pp. 3097-3110. DOI: 10.1016/j.actamat.2004.03.011.

[23] D. Hull and D.J. Bacon, 5 th ed., Butterworth-Heinemann 2011, USA, pp. 114.

[24] Ghosh, A., Brokmeier, H.G., Hamdany, N. Al., Sinha, S., Schell, N., Gurao, N.P. (2018). A Synchrotron X-ray and electron backscatter diffraction based investigation of deformation and failure micro-mechanisms of monotonic and cyclic loading in titanium, Mater. Sci. Eng. A 726, pp. 143-153. DOI: 10.1016/j.msea.2018.04.036. 
[25] Ghosh, A. (2019). Anisotropic tensile and ratcheting behavior of commercially pure titanium processed via cross rolling and annealing, Int. J. fatigue. 120, pp. 12-22. DOI: 10.1016/j.ijfatigue.2018.10.024.

[26] Anahid, M., Ghosh, S. (2013). Homogenised constitutive and fatigue nucleation models from crystal plasticity FE simulations of Ti alloys, Part 2: macroscopic probabilistic crack nucleation model, Int. J. Plasticity. 48, pp. 111-124. DOI: $10.1016 /$ j.ijplas.2013.02.008.

[27] Liakat, M., Khonsari, M.M. (2014). An experimental approach to estimate damage and remaining life of metals under uniaxial fatigue loading, Mat. Des. 57, pp. 289-297. DOI: 10.1016/j.matdes.2013.12.027. 